\title{
Group B Streptococci Exposed to Rifampin or Clindamycin (versus Ampicillin or Cefotaxime) Stimulate Reduced Production of Inflammatory Mediators by Murine Macrophages
}

\author{
KEVIN C. BRINKMANN, AJAY J. TALATI, RAUMINA E. AKBARI, ELIZABETH A. MEALS, AND \\ B. KEITH ENGLISH \\ Department of Pediatrics [K.C.B., A.J.T., R.E.A., E.A.M., B.K.E.], Department of Obstetrics-Gynecology \\ [A.J.T.], University of Tennessee Health Science Center, Children's Foundation Research Center at Le \\ Bonheur Children's Medical Center [K.C.B., A.J.T., E.A.M., B.K.E.], Memphis, Tennessee, 38103
}

\begin{abstract}
ABSTR
Streptococcus agalactiae (group B Streptococcus, GBS) is an
important cause of sepsis and meningitis in neonates, and exces-
sive production of the inflammatory mediators tumor necrosis
factor (TNF) and nitric oxide (NO) causes tissue injury during
severe infections. We hypothesized that exposure of GBS to
different antimicrobial agents would affect the magnitude of the
macrophage inflammatory response to this organism. We stimu-
lated RAW 264.7 murine macrophages with a type-Ia GBS
isolate in the presence of ampicillin, cefotaxime, rifampin, clin-
damycin, or gentamicin, singly or in combination. We found that
GBS exposed to rifampin or clindamycin (versus beta-lactam
antibiotics) stimulated less TNF secretion and inducible nitric
oxide synthase (iNOS) protein accumulation in RAW 264.7
cells. Furthermore, GBS exposed to combinations of antibiotics
that included a protein synthesis inhibitor stimulated less mac-
rophage TNF and iNOS production than did organisms exposed
\end{abstract}
to beta-lactam antibiotics singly or in combination. We conclude that exposure of GBS to rifampin or clindamycin leads to a less pronounced macrophage inflammatory mediator response than does exposure of the organism to cell wall-active antibiotics.

(Pediatr Res 57: 419-423, 2005)

$\quad$ Abbreviations
CSF, cerebrospinal fluid
GBS, group B Streptococcus, Streptococcus agalactiae
iNOS, inducible nitric oxide synthase
LPS, lipopolysaccharide
MIC, minimum inhibitory concentration
NO, nitric oxide
rIFN- $\gamma$, recombinant interferon- $\gamma$
TNF, tumor necrosis factor

Streptococcus agalactiae continues to be an important pathogen in the very young and the very old $(1,2)$. Partial implementation of intrapartum chemoprophylaxis guidelines developed through the collaboration of the Centers for Disease Control and Prevention, the American Academy of Pediatrics, and the American College of Obstetricians and Gynecologists has led to a significant decline in the incidence of early-onset GBS disease in neonates in the United States over the last decade, but the incidence of late-onset GBS disease has not changed $(1,3)$. In addition to the substantial neurologic se-

Received December 29, 2003; accepted August 19, 2004.

Correspondence: Kevin Brinkmann, M.D., East Tennessee Children's Hospital, 2018 Clinch Ave., Knoxville, TN 37916; e-mail: kevinbrinkmann@comcast.net

Supported, in part, by a grant from Le Bonheur Children's Medical Center (Grant \#R073223121, K.C.B.).

These results were presented in part as Abstract \#189 at the Southern Society for Pediatric Research, New Orleans, February 2003, and as Abstract \#1860 at the Society for Pediatric Research, Seattle, May 2003.

DOI: 10.1203/01.PDR.0000153946.97159.79 quelae that can be associated with GBS meningitis (4), case fatality rates of $4 \%$ for early-onset disease and $2.8 \%$ for late-onset disease have been recently reported (3).

The human neonate is an immunocompromised host because of the relative immaturity of the immune system (5). The increased incidence of invasive disease due to GBS in the newborn is due to frequent exposure to the organism (approximately $25 \%$ of women are colonized with GBS) in the context of specific deficiencies of neonatal host defense-particularly the diminished production and delivery of neutrophils to the site of infection and the frequent lack of specific antibody against the infecting serotype (5-7). Neonatal monocytes and macrophages are also impaired compared with macrophages from older children and adults, but are capable of producing large amounts of inflammatory mediators such as TNF in response to GBS $(8,9)$. It is likely that excessive production of inflammatory mediators, including TNF and NO, contributes to the severity of sepsis and meningitis due to GBS, though the 
role of exuberant or unbalanced production of proinflammatory mediators in the pathogenesis of sepsis remains controversial (10).

The host inflammatory response to bacteria is triggered by bacterial products including Gram-negative bacterial endotoxin or LPS, Gram-positive bacterial lipopeptides, bacterial exotoxins, hemolysins, and bacterial DNA (11-16). Some of these bacterial products are secreted (e.g. exotoxins), whereas others are released when the organisms are injured or exposed to antibiotics (e.g. LPS, bacterial DNA) $(11,13,14)$. Antibiotics that lead to rapid cell lysis (e.g. beta-lactams) have been shown to cause a more pronounced release of LPS by Gram-negative bacteria and have been associated with a more intense host inflammatory response $(14,17)$. Beta-lactam treatment of certain Gram-positive bacteria, including Streptococcus pneumoniae and Staphylococcus aureus, has also been reported to trigger a more marked release of bacterial components and a more pronounced host inflammatory response $(14,18)$. These findings may have clinical relevance: in one study, treatment of pneumococcal meningitis in a mouse model with rifampin (versus ceftriaxone) was associated with reductions in the concentrations of bacterial components (lipoteichoic acid and teichoic acid) in the serum and CSF of these animals and with decreased early mortality (19).

Relatively little attention has been paid to the potential role of antibiotic class in the modulation of the host inflammatory response to GBS. We have previously reported that RAW 264.7 murine macrophages exposed to heat-killed or live GBS (in the absence of antibiotics) produce large amounts of TNF (20). In this study, we compared the effects of exposure to cell wall-active antibiotics (ampicillin and cefotaxime) versus protein synthesis inhibitor antibiotics (rifampin, clindamycin, and gentamicin) on the murine macrophage inflammatory response to live GBS.

\section{MATERIALS AND METHODS}

Reagents. Dulbecco's modified Eagle's medium was purchased from Mediatech Inc. (Herndon, VA). L-glutamine was purchased from Invitrogen (Carlsbad, CA). Fetal bovine serum was purchased from Hyclone Laboratories (Logan, UT). LPS purified from Escherichia coli O111:B4 and mouse rIFN- $\gamma$ was purchased from Sigma Chemical Co. (St. Louis, MO). The following antibiotics were purchased from the Department of Pharmacy at Le Bonheur Children's Medical Center: 1) ampicillin for injection, USP (Apothecon B.V., Barneveld, The Netherlands); 2) Claforan (sterile cefotaxime sodium by Aventis, Strasbourg, France); 3) gentamicin for injection, USP (American Pharmaceutical Partners, Inc., Schaumburg, IL); 4) clindamycin for injection, USP (Abbott Laboratories, Abbott Park, IL); and 5) Rifadin IV (rifampin for injection, USP by Aventis). Sterile water for injection, USP (American Pharmaceutical Partners, Inc.) was used for both the reconstitution and dilution of antibiotics to the desired concentrations. Clinically achievable concentrations of antibiotics were used as follows: ampicillin $25 \mu \mathrm{g} / \mathrm{mL}$, cefotaxime 25 $\mu \mathrm{g} / \mathrm{mL}$, gentamicin $5 \mu \mathrm{g} / \mathrm{mL}$, clindamycin $10 \mu \mathrm{g} / \mathrm{mL}$, and rifampin $20 \mu \mathrm{g} / \mathrm{mL}$. These antibiotic concentrations were equal to or exceeded the MIC of the GBS isolate by at least 10 -fold.

Bacteria. A previously studied (20) type-Ia GBS isolated from a neonatal patient with sepsis was used. The GBS isolate was susceptible to all antimicrobials used in this study with MIC as follows: ampicillin $\leq 0.25 \mu \mathrm{g} / \mathrm{mL}$, cefotaxime $0.064 \mu \mathrm{g} / \mathrm{mL}$, gentamicin $\leq 0.5 \mu \mathrm{g} / \mathrm{mL}$, rifampin $\leq 0.5 \mu \mathrm{g} / \mathrm{mL}$, and clindamycin $<0.25 \mu \mathrm{g} / \mathrm{mL}$. MIC were determined by the clinical microbiology laboratory at Le Bonheur Children's Medical Center using the VITEK 2 system (bioMérieux, Marcy l'Etoile, France).

For experiments, the bacteria were grown at $37^{\circ} \mathrm{C}$ in trypticase soy broth (BD, Franklin Lakes, NY), washed three times in endotoxin-free PBS, and the concentration was determined by colony counts. Final concentrations of $10^{6}$ and $10^{7} \mathrm{cfu} / \mathrm{mL}$ were used in experiments, based upon our previous experience (20) and our preliminary studies.

Cells and cell culture. RAW 264.7 cells were purchased from America Type Culture Collection (Manassas, VA) and cultured in antibiotic-free Dulbecco's modified Eagle's medium supplemented with $10 \%$ fetal bovine serum and $2 \mathrm{mM}$ L-glutamine. Experiments were done in 6-well tissue culture plates (BD) with $4.00-4.68 \times 10^{6}$ cells/well or in 24 -well tissue culture plates with $1 \times 10^{6}$ cells/well (24-well experiments were for TNF determination only). Cells were exposed to the appropriate antibiotic(s) and then to the GBS isolate and incubated for $18 \mathrm{~h}$-we determined this to be the optimal incubation time based upon our previous experience and our preliminary studies. In the studies of iNOS protein accumulation, cells were also exposed to low concentrations of rIFN- $\gamma$, which was required for iNOS production in response to the GBS isolate. We have previously reported that co-incubation with low doses of rIFN- $\gamma$ was required for induction of iNOS protein accumulation in RAW 264.7 cells stimulated with either antibiotic-treated $S$. pneumoniae $(18,21)$, lipoteichoic acid purified from viridans streptococci (12), or pyrogenic exotoxins A or C isolated from Streptococcus pyogenes (23).

Immunoblotting. Cells were first lysed with an extraction buffer $(20 \mathrm{mM}$ Tris, $100 \mathrm{mM} \mathrm{NaCl}, 1 \%$ Triton X-100, $50 \mathrm{mM} \mathrm{NaF}, 1 \mathrm{mM} \mathrm{Na}_{3} \mathrm{VO}_{4}, 0.2 \mathrm{mM}$ phenylmethylsulfonyl fluoride, $10 \mu \mathrm{g} / \mathrm{mL}$ leupeptin, and $10 \mu \mathrm{g} / \mathrm{mL}$ aprotinin). These lysates were then frozen at $-20^{\circ} \mathrm{C}$ until they were assayed. The lysates, $100 \mu \mathrm{g}$ of protein each, were electrophoresed on $7.5 \%$ SDS-polyacrylamide gels and then transferred to nitrocellulose membranes and blocked overnight in $5 \%$ milk with tris-buffered saline. Nitrocellulose membranes were next reacted with murine MAb specific for iNOS (Transduction Laboratories, Lexington, $\mathrm{KY}$ ). Blots were then reacted with a sheep anti-mouse $\operatorname{IgG}$ peroxidase-linked conjugate (Amersham Biosciences AB, Uppsala, Sweden) and iNOS protein was detected by enhanced chemiluminescence (Amersham Biosciences AB) and band intensities were quantitated by using a Bio-Rad Model GS-700 densitometer (Bio-Rad, Hercules, CA).

Measurement of TNF concentrations. Cell-free supernatants were collected from each experimental well and stored at $-20^{\circ} \mathrm{C}$ until they were assayed. TNF concentrations in cell supernatants were quantitated using a solid phase sandwich ELISA specific for murine TNF, as specified by the manufacturer (R \& D Systems, Minneapolis, MN).

Statistical analysis. Paired two-tailed $t$ tests were used to compare iNOS accumulation and TNF secretion by RAW 264.7 cells in response to stimulation with GBS and antibiotics. A $p$ value $<0.05$ was considered significant.

\section{RESULTS}

GBS exposed to rifampin or clindamycin (compared with cefotaxime or ampicillin) stimulated substantially less TNF production by RAW 264.7 murine macrophages. In our preliminary studies, we found that live GBS at $10^{6}$ and $10^{7} \mathrm{cfu} / \mathrm{mL}$ exposed to beta-lactam antibiotics consistently stimulated large amounts of TNF secretion and iNOS protein accumulation by RAW 264.7 cells cultured for $18 \mathrm{~h}$ (not shown). Subsequently, cells were stimulated with GBS, at concentrations of $10^{6}$ and $10^{7}$ $\mathrm{cfu} / \mathrm{mL}, \mathrm{rIFN}-\gamma$, and either ampicillin, cefotaxime, rifampin, or clindamycin for $18 \mathrm{~h}$. Figure 1 depicts mean TNF secretion from eight experiments using GBS at $10^{7} \mathrm{cfu} / \mathrm{mL}$. As compared with exposure to beta-lactam antibiotics, exposure of GBS to rifampin led to significantly less TNF secretion (56\% less than cefotaxime, $p=0.008 ; 47 \%$ less than ampicillin, $p=0.024$ ). A significantly lower amount of TNF was also produced by RAW 264.7 cells exposed to GBS in the presence of clindamycin as compared with cefotaxime (50\% less, $p=0.011$ ) or ampicillin (38\% less, $p=$ $0.033)$. Results from experiments using GBS at $10^{6} \mathrm{cfu} / \mathrm{mL}$ were similar (not shown). Antibiotics alone did not induce TNF secretion (not shown).

GBS exposed to rifampin or clindamycin (compared with cefotaxime or ampicillin) stimulated substantially less iNOS protein accumulation by RAW 264.7 murine macrophages. RAW 264.7 cells were stimulated with GBS, at concentrations of $10^{6}$ and $10^{7} \mathrm{cfu} / \mathrm{mL}$, a low concentration of rIFN- $\gamma(10$ $\mathrm{U} / \mathrm{mL}$ ), and either ampicillin, cefotaxime, rifampin, or clinda- 


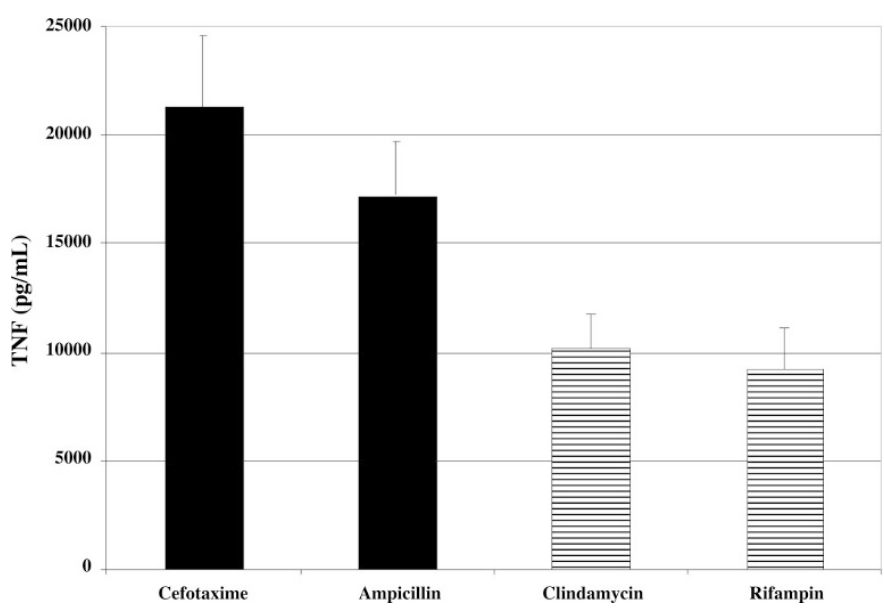

Figure 1. Effect of different antibiotics on GBS-mediated TNF secretion in RAW 264.7 macrophages. Mean TNF production $(\mathrm{pg} / \mathrm{mL}) \pm$ SE by RAW 264.7 cells from eight experiments in response to stimulation with $10^{7} \mathrm{cfu} / \mathrm{mL}$ of GBS Ia, rIFN- $\gamma$, and either ampicillin $(25 \mu \mathrm{g} / \mathrm{mL})$, cefotaxime $(25 \mu \mathrm{g} / \mathrm{mL})$, clindamycin $(10 \mu \mathrm{g} / \mathrm{mL})$, or rifampin $(20 \mu \mathrm{g} / \mathrm{mL})$ is shown. Compared with beta-lactam antibiotics, exposure of the GBS isolate to rifampin or clindamycin led to significantly less TNF secretion [rifampin: 56\% less than cefotaxime ( $p$ $=0.008), 47 \%$ less than ampicillin $(p=0.024)$; clindamycin: $50 \%$ less than cefotaxime $(p=0.011), 38 \%$ less than ampicillin $(p=0.033)$ ].

mycin. Our preliminary experiments demonstrated no detectable iNOS protein accumulation by cells exposed to GBS and antibiotics in the absence of rIFN- $\gamma$ (not shown), consistent with our previous studies of iNOS up-regulation by other Gram-positive bacteria (18,21-23). Stimulation of RAW 264.7 cells with GBS exposed to rifampin or clindamycin led to markedly less iNOS protein accumulation compared with the cefotaxime or ampicillin experimental groups (Fig. 2 is representative, $n=5$ ). Compared with exposure to cefotaxime, exposure of GBS $10^{7} \mathrm{cfu} / \mathrm{mL}$ to protein synthesis-inhibiting antibiotics led to significantly less iNOS protein accumulation (67\% less in rifampin group, $p=0.039$; $63 \%$ less in clindamycin group, $p=0.047$ ). Antibiotics alone or in combination with rIFN- $\gamma$ did not stimulate detectable amounts of iNOS protein accumulation by these cells (not shown).

GBS exposed to combinations of antibiotics that included either rifampin or clindamycin stimulated substantially less TNF and iNOS protein accumulation by RAW 264.7 murine macrophages. GBS exposed to combinations of antibiotics including a protein synthesis inhibitor (either rifampin, clindamycin, or gentamicin) plus a beta-lactam (either ampicillin or cefotaxime) consistently stimulated less TNF secretion (Fig. 3)

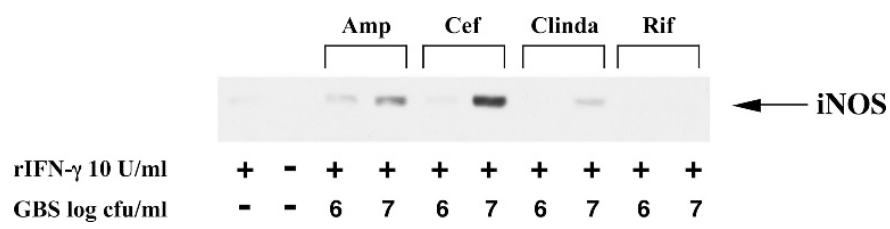

Figure 2. Effect of different antibiotics on GBS-mediated stimulation of iNOS protein accumulation in RAW 264.7 macrophages. A representative immunoblot demonstrating iNOS protein accumulation by RAW 264.7 cells that were stimulated with $10^{6}$ or $10^{7} \mathrm{cfu} / \mathrm{mL}$ of GBS Ia, rIFN- $\gamma$, and either ampicillin (Amp, $25 \mu \mathrm{g} / \mathrm{mL})$, cefotaxime (Cef, $25 \mu \mathrm{g} / \mathrm{mL})$, clindamycin (Clinda, $10 \mu \mathrm{g} / \mathrm{mL}$ ), or rifampin (Rif, $20 \mu \mathrm{g} / \mathrm{mL}$ ) is shown.
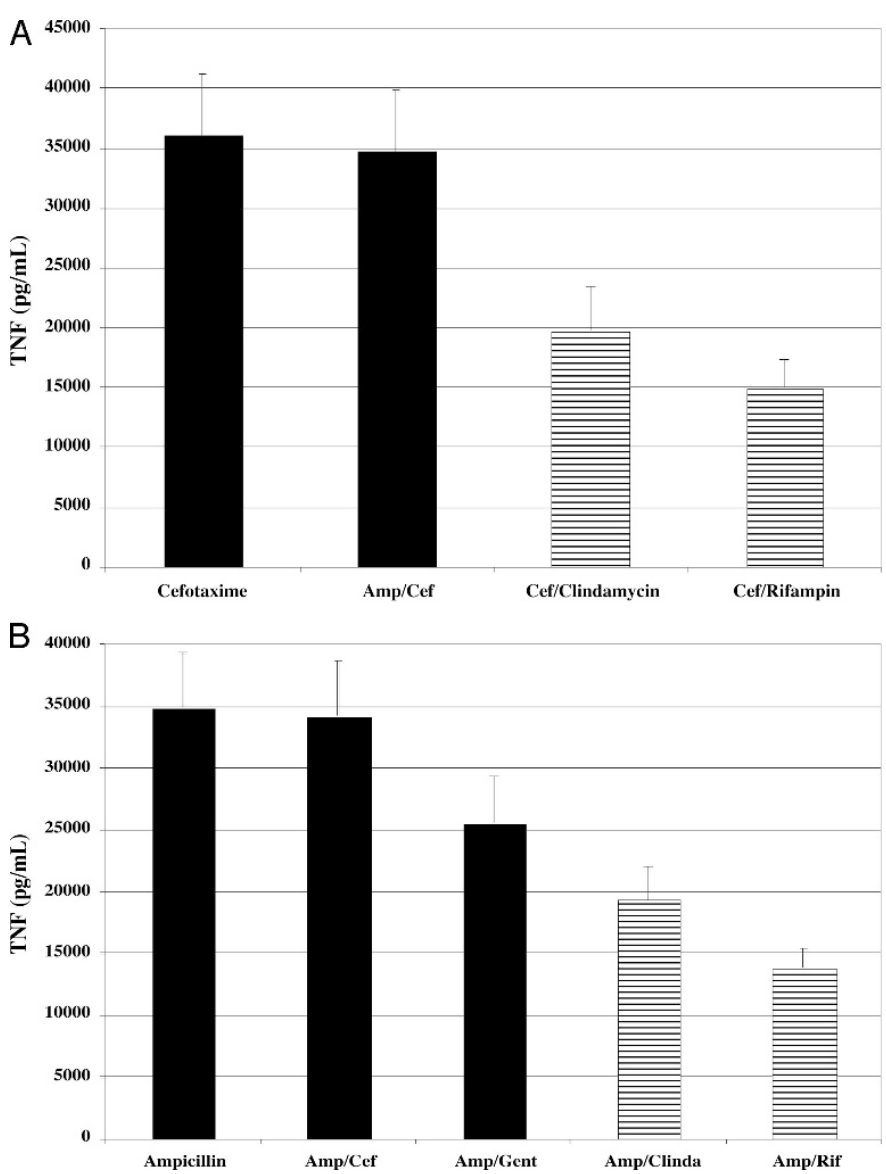

Figure 3. Effects of combinations of antibiotics on GBS-mediated TNF secretion in RAW 264.7 macrophages. RAW 264.7 cells were stimulated with $10^{7} \mathrm{cfu} / \mathrm{mL}$ of GBS Ia, rIFN- $\gamma$, and either $(A)$ cefotaxime $($ Cef, $25 \mu \mathrm{g} / \mathrm{mL})$, ampicillin (Amp, $25 \mu \mathrm{g} / \mathrm{mL})+$ Cef, Cef + clindamycin (Clinda, $10 \mu \mathrm{g} / \mathrm{mL})$, or Cef + rifampin $($ Rif, $20 \mu \mathrm{g} / \mathrm{mL})(n=7)$; or $(B)$ Amp, Amp + Cef, Amp + gentamicin $($ Gent, $5 \mu \mathrm{g} / \mathrm{mL})$, Amp + Clinda, or Amp + Rif $(n=8)$. Mean TNF concentrations are shown. Compared with Cef alone $(A)$, exposure of GBS to combinations of Cef + Amp led to $97 \%$ (range, $79-102 \% ; p=0.74$ ) as much TNF secretion, whereas exposure to Cef + Clinda or Cef + Rif resulted in significantly less TNF secretion: $53 \%$ (range, $41-68 \% ; p=0.026$ ) as much for Cef + Clinda, and $42 \%$ (range, $27-52 \% ; p=0.001$ ) as much for Cef + Rif. For comparisons with Amp alone in $(B)$, exposure of GBS to combinations of Amp + Cef led to $99 \%$ (range, $84-117 \% ; p=0.92$ ) as much TNF secretion, whereas exposure to Amp + Gent resulted in $72 \%$ (range, $55-84 \% ; p=0.13)$ as much TNF secretion. However, exposure to Amp + Clinda or Amp + Rif resulted in significantly less TNF secretion: 55\% (range, $45-72 \% ; p=0.011$ ) as much for Amp + Clinda and 42\% (range, 27-55\%; $p$ $=0.001)$ as much for Amp + Rif.

and less iNOS protein accumulation (Fig. 4) by RAW 264.7 cells compared with stimulation with GBS exposed to betalactams alone or in combination with another beta-lactam drug. The magnitude of the reductions in TNF and iNOS production was comparable to that observed when GBS were exposed to rifampin or clindamycin alone.

As compared with exposure to cefotaxime alone, exposure of GBS $10^{7} \mathrm{cfu} / \mathrm{mL}$ to cefotaxime plus rifampin resulted in $58 \%$ less TNF secretion ( $p=0.001, n=7)$ and $71 \%$ less iNOS protein accumulation ( $p=0.003, n=6)$, whereas exposure to cefotaxime plus clindamycin led to $47 \%$ less TNF secretion $(p=$ $0.026, n=7)$ and $67 \%$ less iNOS protein accumulation $(p=$ $0.003, n=6$ ) (Fig. $3 A$ and Fig. $4 B$ ). Addition of either rifampin 


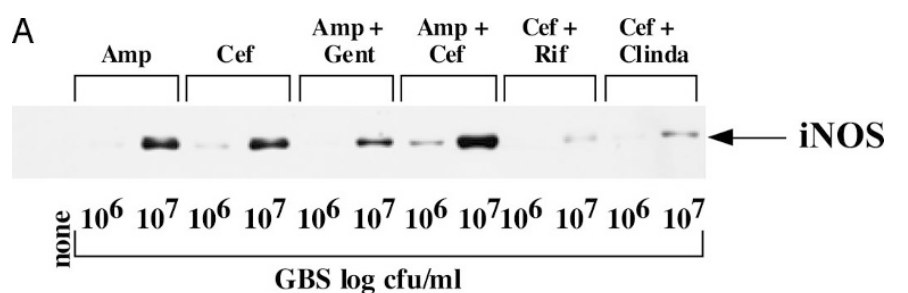

B

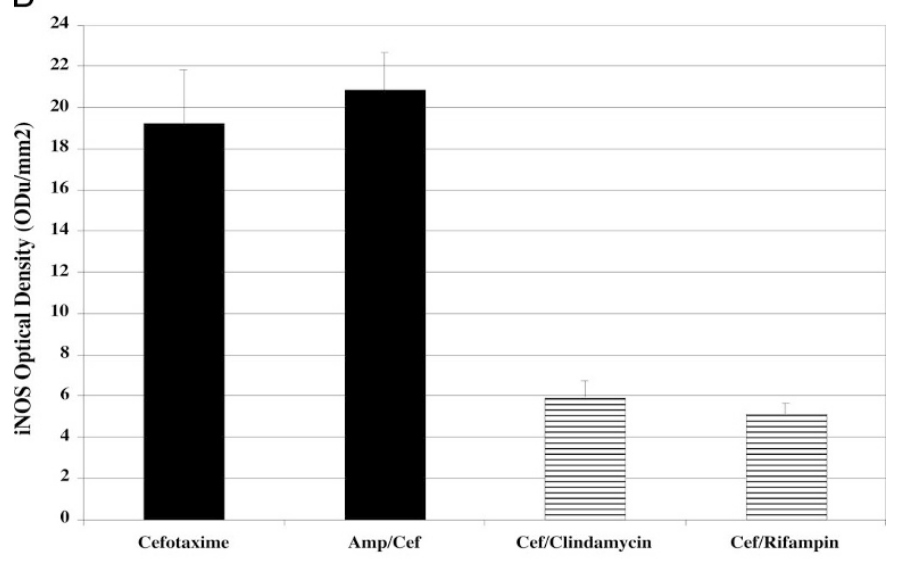

$C_{18}$

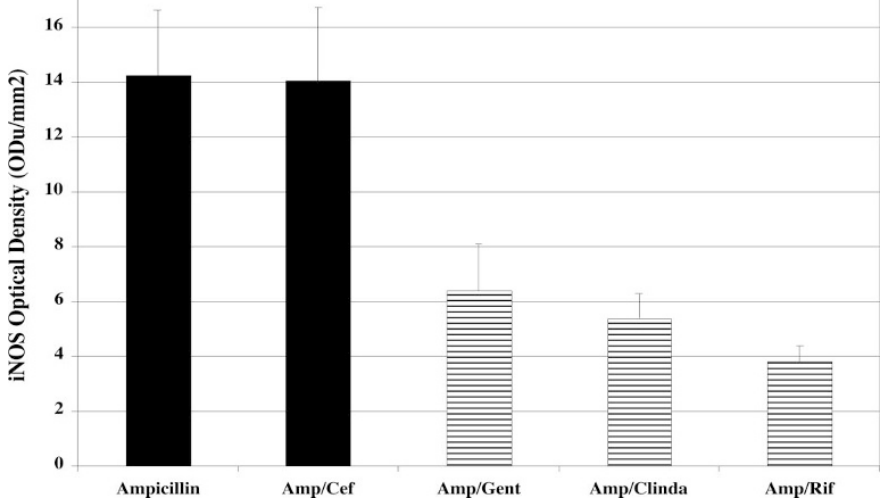

Figure 4. Effects of combinations of antibiotics on GBS-stimulated iNOS protein accumulation in RAW 264.7 murine macrophages. (A) Representative immunoblot detecting iNOS protein accumulation by RAW 264.7 cells stimulated with $10^{6}$ or $10^{7} \mathrm{cfu} / \mathrm{mL}$ of GBS Ia, rIFN- $\gamma$, and either ampicillin (Amp, $25 \mu \mathrm{g} / \mathrm{mL}$ ), cefotaxime (Cef, $25 \mu \mathrm{g} / \mathrm{mL})$, Amp + gentamicin (Gent, $5 \mu \mathrm{g} / \mathrm{mL})$, Amp + Cef, Cef + rifampin (Rif, $20 \mu \mathrm{g} / \mathrm{mL}$ ), or Cef + clindamycin (Clinda, $10 \mu \mathrm{g} / \mathrm{mL})$. ( $B, C)$ Mean OD of iNOS protein bands from six experiments. Compared with Cef alone $(B)$, exposure of GBS to combinations of Cef + Amp led to $115 \%$ (range, $76-158 \% ; p=0.62$ ) as much iNOS accumulation, whereas exposure to Cef + Clinda or Cef + Rif resulted in significantly less iNOS accumulation: $33 \%$ (range, $18-44 \% ; p=0.003$ ) as much for Cef + Clinda and 29\% (range, 16-43\%; $p=0.003$ ) as much for Cef + Rif. For comparisons with Amp alone in $(C)$, exposure of GBS to combinations of Amp + Cef led to $97 \%$ (range, $79-132 \% ; p=0.96$ ) as much iNOS accumulation, whereas exposure to Amp + either Gent, Clinda, or Rif resulted in significantly less iNOS accumulation: $44 \%$ (range, $28-72 \% ; p=0.025$ ) as much for Amp + Gent; 42\% (range, 23-91\%; $p=0.013$ ) for Amp + Clinda; and 28\% (range, $19-40 \% ; p=0.005$ ) for Amp + Rif.

or clindamycin to ampicillin also led to significant reductions of both TNF secretion and iNOS protein accumulation (Fig. $3 B$ and Fig. $4 C$ ). In contrast, the addition of gentamicin to ampicillin resulted in smaller reductions in TNF secretion and iNOS protein accumulation (Fig. $3 B$ and Fig. 4C). Addition of rifampin (compared with clindamycin or gentamicin) to either cefotaxime or ampicillin (Figs. 3 and 4) resulted in the largest reduction in TNF secretion and iNOS protein accumulation.

\section{DISCUSSION}

In this study, we found that GBS exposed to either of two protein synthesis inhibiting antibiotics (rifampin or clindamycin) singly or in combination with a beta-lactam antibiotic (ampicillin or cefotaxime), triggered less macrophage TNF secretion and iNOS protein accumulation compared with GBS exposed to beta-lactam antibiotics singly or in combination with another beta-lactam antibiotic. Current empiric treatment regimens for the neonatal patient with suspected sepsis or meningitis frequently include combinations of ampicillin plus either gentamicin or cefotaxime. These combinations of antibiotics are active against most of the bacterial pathogens that cause neonatal bacteremia and meningitis, including GBS. Many experts recommend ampicillin or penicillin in combination with gentamicin as initial therapy for suspected early-onset bacterial infections in neonates (because of the potential for synergistic killing of GBS and other neonatal pathogens, including the Enterococcus), followed by monotherapy with ampicillin or penicillin alone when GBS is isolated $(7,24)$. These regimens have the advantage of proven safety and efficacy for the treatment of GBS infections, but it is not known whether this represents optimal therapy.

Recent advances in our understanding of the role of inflammatory mediators in the pathogenesis of sepsis and meningitis have led to optimism regarding the potential development of new adjunctive therapies for these serious infections (25), but this promise remains largely unfulfilled (10). Treatment of GBS infections with antimicrobial agents that effectively eradicate the infection while leading to a less pronounced inflammatory response might result in reduced morbidity or mortality. In experimental models of meningitis, the release of bacterial components into the CSF is associated with increased meningeal inflammation, increased intracranial pressure, and increased cerebral edema (26-29). Treatment with cefotaxime in an experimental model of Gram-negative meningitis was associated with increased cerebral edema as compared with chloramphenicol (30). Similarly, treatment of experimental pneumococcal meningitis with rifampin (compared with ceftriaxone) led to an improved outcome, a decrease in reactive oxygen species, and reduced apoptosis of neurons in the dentate gyrus (31).

The underlying mechanisms accounting for the attenuated macrophage inflammatory response in cells exposed to GBS in the presence of rifampin or clindamycin are not known, but it is likely that this reflects diminished release of proinflammatory components of the organism. Although we used relatively high concentrations of GBS $\left(10^{6}\right.$ and $\left.10^{7} \mathrm{cfu} / \mathrm{mL}\right)$ in our study, these concentrations are similar to those previously used by us $(18,20)$ and others $(8,15)$ and correspond to bacterial concentrations documented in some patients with meningitis (32). The commonly used regimen of ampicillin plus gentamicin may be comparable to regimens using other protein synthesis inhibitors in the therapy of some (but not all) infections, given the poor penetration of aminoglycosides into 
certain anatomic locations, especially the CSF. Combinations of a beta-lactam plus rifampin were comparable to the combination of ampicillin and gentamicin in this study and may be more efficacious in the clinical setting of meningitis due to better CSF penetration of rifampin compared with gentamicin. Our data suggest that protein synthesis-inhibiting antibiotics (alone or in combination with beta-lactams) should be studied in animal models of GBS sepsis and meningitis.

Acknowledgments. The authors thank the staff of the microbiology department at Le Bonheur Children's Medical Center for performing the MIC determinations, the pharmacy staff at Le Bonheur Children's Medical Center for their aid in obtaining the antibiotics used, and Steven Buckingham, M.D., for his careful reading of the manuscript.

\section{REFERENCES}

1. Schrag S, Gorwitz R, Fultz-Butts K, Schuchat A 2002 Prevention of perinatal group B streptococcal disease. Revised guidelines from CDC. MMWR Recomm Rep 51:1-22

2. Farley MM, Harvey RC, Stull T, Smith JD, Schuchat A, Wenger JD, Stephens DS 1993 A population-based assessment of invasive disease due to group B Streptococcus in nonpregnant adults. N Engl J Med 328:1807-1811

3. Schrag SJ, Zywicki S, Farley MM, Reingold AL, Harrison LH, Lefkowitz LB, Hadler JL, Danila R, Cieslak PR, Schuchat A 2000 Group B streptococcal disease in the era of intrapartum antibiotic prophylaxis. N Engl J Med 342:15-20

4. Edwards MS, Rench MA, Haffar AA, Murphy MA, Desmond MM, Baker CJ 1985 Long-term sequelae of group B streptococcal meningitis in infants. J Pediatr 106:717722

5. English BK, Schroeder HW, Wilson CB 2001 Immaturity of the fetal and neonatal immune system. In: Rich RR, Shearer WT, Kotzin BL, Schroeder HW (eds) Clinical Immunology: Principles and Practice, 2nd Ed, Vol I. Mosby, London, pp 40.1-40.10

6. Christensen RD, Rothstein G 1980 Exhaustion of mature marrow neutrophils in neonates with sepsis. J Pediatr 96:316-318

7. Rowen JL, Baker CJ 2004 Group B streptococcal infections. In: Feigin RD, Cherry JD, Demmler, GJ, Kaplan, SL (eds) Textbook of Pediatric Infectious Diseases, 5th Ed, Vol I. W.B. Saunders, Philadelphia, pp 1156-1175

8. Williams PA, Bohnsack JF, Augustine NH, Drummond WK, Rubens CE, Hill HR 1993 Production of tumor necrosis factor by human cells in vitro and in vivo, induced by group B streptococci. J Pediatr 123:292-300

9. Kwak DJ, Augustine NH, Borges WG, Joyner JL, Green WF, Hill HR 2000 Intracellular and extracellular cytokine production by human mixed mononuclear cells in response to group B streptococci. Infect Immun 68:320-327

10. Hotchkiss RS, Karl IE 2003 The pathophysiology and treatment of sepsis. N Engl J Med 348:138-150

11. Beutler B, Cerami A 1989 The biology of cachectin/TNF-a primary mediator of the host response. Annu Rev Immunol 7:625-655

12. English BK, Patrick CC, Orlicek SL, McCordic R, Shenep JL 1996 Lipoteichoic acid from viridans streptococci induces the production of tumor necrosis factor and nitric oxide by murine macrophages. J Infect Dis 174:1348-1351
13. Bohach GA, Fast DJ, Nelson RD, Schlievert PM 1990 Staphylococcal and streptococcal pyrogenic toxins involved in toxic shock syndrome and related illnesses. Crit Rev Microbiol 17:251-272

14. Nau R, Eiffert H 2002 Modulation of release of proinflammatory bacterial compounds by antibacterials: potential impact on course of inflammation and outcome in sepsis and meningitis. Clin Microbiol Rev 15:95-110

15. Ring A, Braun JS, Nizet V, Stremmel W, Shenep JL 2000 Group B streptococcal beta-hemolysin induces nitric oxide production in murine macrophages. J Infect Dis 182:150-157

16. Weiner GJ 2000 The immunobiology and clinical potential of immunostimulatory CpG oligodeoxynucleotides. J Leukoc Biol 68:455-463

17. Prins JM, van Agtmael MA, Kuijper EJ, van Deventer SJ, Speelman P 1995 Antibiotic-induced endotoxin release in patients with Gram-negative urosepsis: double-blind study comparing imipenem and ceftazidime. J Infect Dis 172:886-891

18. Orman KL, English BK 2000 Effects of antibiotic class on the macrophage inflammatory response to Streptococcus pneumoniae. J Infect Dis 182:1561-1565

19. Nau R, Wellmer A, Soto A, Koch K, Schneider O, Schmidt H, Gerber J, Michel U, Bruck W 1999 Rifampin reduces early mortality in experimental Streptococcus pneumoniae meningitis. J Infect Dis 179:1557-1560

20. Talati AJ, Crouse DT, English BK, Newman C, Harrison L, Meals E 2001 Immunomodulation by exogenous surfactant: effect on TNF-alpha secretion and luminolenhanced chemiluminescence activity by murine macrophages stimulated with group B streptococci. Microbes Infect 3:267-273

21. Orman KL, Shenep JL, English BK 1998 Pneumococci stimulate the production of the inducible nitric oxide synthase and nitric oxide by murine macrophages. J Infect Dis 178:1649-1657

22. Deleted in proof

23. Christ EA, Meals E, English BK 1997 Streptococcal pyrogenic exotoxins A (SpeA) and $\mathrm{C}$ (SpeC) stimulate the production of inducible nitric oxide synthase (iNOS) protein in RAW 264.7 macrophages. Shock 8:450-453

24. Saez-Llorens X, McCracken GH 2004 Perinatal bacterial diseases. In: Feigin RD, Cherry JD, Demmler GJ, Kaplan SL (eds) Textbook of Pediatric Infectious Diseases, 5th Ed, Vol I. W.B. Saunders, Philadelphia, pp 929-966

25. Doughty LA, Kaplan SS, Carcillo JA 1996 Inflammatory cytokine and nitric oxide responses in pediatric sepsis and organ failure. Crit Care Med 24:1137-1143

26. Mustafa MM, Mertsola J, Ramilo O, Saez-Llorens X, Risser RC, McCracken GH J 1989 Increased endotoxin and interleukin-1 beta concentrations in cerebrospinal fluid of infants with coliform meningitis and ventriculitis associated with intraventricular gentamicin therapy. J Infect Dis 160:891-895

27. Burroughs M, Rozdzinski E, Geelen S, Tuomanen E 1993 A structure-activity relationship for induction of meningeal inflammation by muramyl peptides. J Clin Invest 92:297-302

28. Schneider O, Michel U, Zysk G, Dubuis O, Nau R 1999 Clinical outcome in pneumococcal meningitis correlates with CSF lipoteichoic acid concentrations. Neurology 53:1584-1587

29. Tuomanen E, Liu H, Hengstler B, Zak O, Tomasz A 1985 The induction of meningeal inflammation by components of the pneumococcal cell wall. J Infect Dis 151:859868

30. Tauber MG, Shibl AM, Hackbarth CJ, Larrick JW, Sande MA 1987 Antibiotic therapy, endotoxin concentration in cerebrospinal fluid, and brain edema in experimental Escherichia coli meningitis in rabbits. J Infect Dis 156:456-462

31. Bottcher T, Gerber J, Wellmer A, Smirnov AV, Fakhrjanali F, Mix E, Pilz J, Zettl UK, Nau R 2000 Rifampin reduces production of reactive oxygen species of cerebrospinal fluid phagocytes and hippocampal neuronal apoptosis in experimental Streptococcus pneumoniae meningitis. J Infect Dis 181:2095-2098

32. Feldman WE 1976 Concentrations of bacteria in cerebrospinal fluid of patients with bacterial meningitis. J Pediatr 88:549-552 